\title{
A case of intractable infectious keratitis and subsequent flap necrosis after laser in situ keratomileusis
}

This article was published in the following Dove Press journal:

Clinical Ophthalmology

16 September 2009

Number of times this article has been viewed

\author{
Kazutaka Kamiya \\ Masayuki Kasahara \\ Kimiya Shimizu \\ Department of Ophthalmology, \\ University of Kitasato \\ School of Medicine, Japan
}

Correspondence: Kazutaka Kamiya Department of Ophthalmology, University of Kitasato School of Medicine, I-I5-I Kitasato, Sagamihara, Kanagawa, 228-8555, Japan

Tel +8I 427789012

Fax +8I 427789920

Email kamiyak-tky@umin.ac.jp
Abstract: We report on a patient in whom intractable infectious keratitis and subsequent lamellar flap necrosis necessitating flap amputation after laser in situ keratomileusis (LASIK). A 34-year-old woman undergoing LASIK complained of blurred vision and pain in the left eye. The best spectacle-corrected visual acuity was 0.01 , and slit-lamp examination showed a marked presence of stromal infiltrates involving the flap and the underlying stroma in that eye. The patient was treated topically with hourly instillation of micronomicin, levofloxacin, and cefmenoxime, together with systemic administration of imipenem, but the left eye developed corneal flap necrosis. We performed surgical debridement of the diseased stroma and excised the lamellar flap. Since nontuberculous mycobacterium was detected on the surgical instruments, we then added oral clarithromycin, and substituted systemic administration of amikacin with that of imipenem. At one month after the flap removal, the visual acuity gradually improved to 0.7 , but the stromal opacity of the central cornea and hyperopic shift of +3.0 diopters remained. LASIK can cause intractable keratitis, resulting in significant visual disturbance that presumably results from insufficient antisepsis of the medical instruments used for this surgery, supporting the importance of strict sterilization of these instruments.

Keywords: infectious keratitis, flap necrosis, nontuberculous mycobacterium, sterilization, LASIK

\section{Introduction}

Laser in situ keratomileusis (LASIK) has gained popularity as an effective means of correcting refractive errors. The onset of infectious keratitis after LASIK has been reported to be a rare complication, but may lead to impairment of visual performance. ${ }^{1-3}$ It has been demonstrated that infectious keratitis caused by mycobacterium occurs after LASIK. $^{2-5}$ We present a case in which intractable infectious keratitis and subsequent lamellar flap necrosis necessitating flap amputation, both presumably resulting from inappropriate sterilization of surgical instruments, occur after LASIK, resulting in significant visual disturbance.

\section{Case report}

A 34-year-old woman who had undergone bilateral LASIK one month earlier at another eye clinic was referred to our hospital complaining of blurred vision and pain in the left eye. The best spectacle-corrected visual acuity (BSCVA) on the initial visit was 0.01 , and slit-lamp examination showed a marked presence of stromal infiltrates involving the flap and the underlying stroma in that eye (Figure 1). Other ophthalmic examination findings were unremarkable. Corneal scrapings were taken, but the 


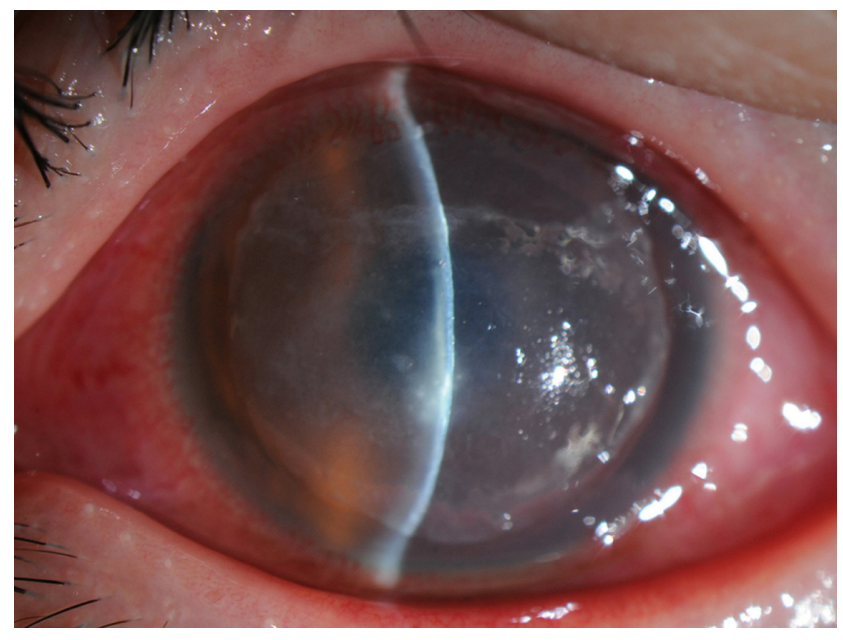

Figure I Slit-lamp examination shows marked presence of stromal infiltrates involving the flap and the underlying stroma.

results were negative. The stromal bed was irrigated with micronomicin solutions, and the flap was repositioned at the end of the procedure. The patient was treated topically with hourly instillation of $0.3 \%$ micronomicin, $0.5 \%$ levofloxacin, and $0.5 \%$ cefmenoxime, together with systemic administration of imipenem ( $2 \mathrm{~g} /$ day). One week after our initial treatment, the left eye developed corneal flap necrosis and deterioration of other clinical findings. After obtaining informed consent, we performed surgical debridement of the diseased stroma and excised the lamellar flap to facilitate drug penetration. Since the health care center disclosed that nontuberculous mycobacterium was detected on the surgical instruments, including the microkeratomes, we then added oral clarithromycin (400 mg/day), and substituted systemic administration of amikacin (400 mg/day) with that of imipenem as the treatment regimen. At one month after the flap removal, the BSCVA gradually improved to 0.7 , but the stromal opacity of the central cornea and hyperopic shift of +3.0 diopters (D) remained (Figure 2). No complications (such as iatrogenic keratectasia or recurrent infection) occurred during the three-month observation period.

\section{Discussion}

Mycobacterium is an aerobic, Gram-positive bacterium that is present extensively in the environment, for example, in dust, water, soil, and on animals. It has been reported to be one of the major causative organisms of infectious keratitis after LASIK, appearing especially in the late postoperative period. ${ }^{2-5}$ A cluster of 67 cases of infectious keratitis after LASIK appeared between September 2008 and January 2009 in the referring institution and nontuberculous mycobacterium

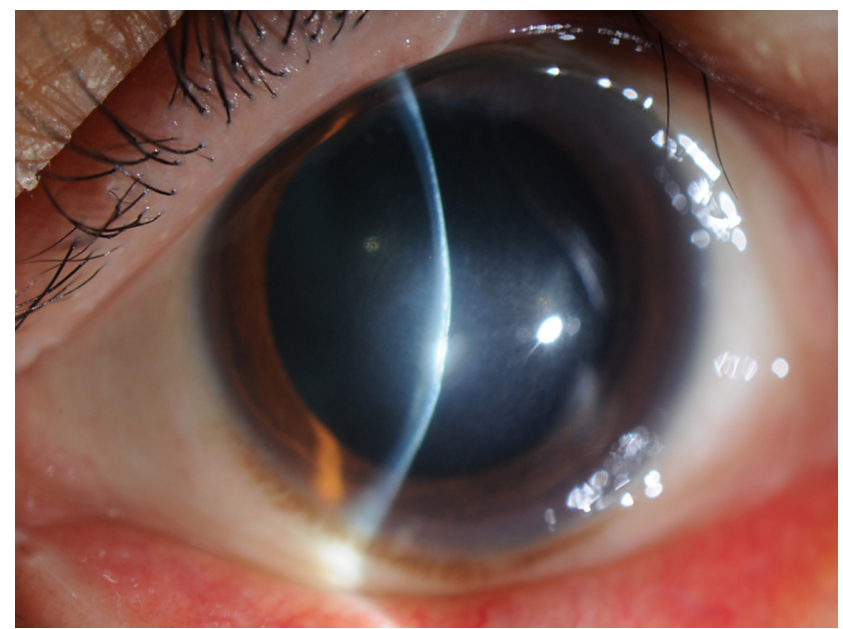

Figure $\mathbf{2}$ Slit-lamp examination shows the remaining stromal opacity of the central cornea.

was isolated from surgical instruments, according to the health care center. Moreover, the antibiotic therapy used initially was not very effective against this post-LASIK keratitis. Thus, we strongly suspect that this infection was caused by nontuberculous mycobacterium, possibly due to intraoperative contamination, although we did not identify the causative organism in our cultures of corneal scrapings. If the organism cultured from corneal scrapings had been in accordance with nontuberculous mycobacterium isolated from surgical instruments, we would have been able to confirm the authenticity of the results. The information from the health care center appears to support the importance of strict sterilization of the medical instruments used for refractive surgery.

This case report emphasizes the difficulties of management of infectious keratitis after LASIK. The patient was treated empirically without microbiologic investigation, resulting in delay of diagnosis and appropriate therapy in this institution. Although a variety of organisms may be involved in infectious keratitis occurring after LASIK, ${ }^{1-3}$ we should bear in mind that nontuberculous mycobacterium is a possible source of severe post-LASIK infection.

Our findings indicate that LASIK can cause intractable keratitis, resulting in significant visual disturbance that presumably results from insufficient antisepsis of the medical instruments used for this surgery. Surgeons must be responsible for strict sterilization, since this can reduce the risk of infectious keratitis after refractive surgery.

\section{Disclosures}

The authors have no financial or proprietary interests in the materials presented herein. 


\section{References}

1. Gimbel HV, Penno EE, van Westenbrugge JA, Ferensowicz M, Furlong MT. Incidence and management of intraoperative and early postoperative complications in 1000 consecutive laser in situ keratomileusis cases. Ophthalmology. 1998;105:1839-1847.

2. Solomon R, Donnenfeld ED, Azar DT, et al. Infectious keratitis after laser in situ keratomileusis: results of an ASCRS survey. J Cataract Refract Surg. 2003;29:2001-2006.

3. Chang MA, Jain S, Azar DT. Infections following laser in situ keratomileusis: an integration of the published literature. Surv Ophthalmol. 2004;49:269-280.
4. Winthrop KL, Steinberg EB, Holmes G, et al. Epidemic and sporadic cases of nontuberculous mycobacterial keratitis associated with laser in situ keratomileusis. Am J Ophthalmol. 2003;135:223-224.

5. John T, Velotta E. Nontuberculous (atypical) mycobacterial keratitis after LASIK: current status and clinical implications. Cornea. $2005 ; 24: 245-255$.

\section{Publish your work in this journal}

Clinical Ophthalmology is an international, peer-reviewed journal covering all subspecialties within ophthalmology. Key topics include: Optometry; Visual science; Pharmacology and drug therapy in eye diseases; Basic Sciences; Primary and Secondary eye care; Patien Safety and Quality of Care Improvements. This journal is indexed on

Submit your manuscript here: http://www.dovepress.com/clinical-ophthalmology-journal

\section{Dovepress}

PubMed Central and CAS, and is the official journal of The Society of Clinical Ophthalmology (SCO). The manuscript management system is completely online and includes a very quick and fair peer-review system, which is all easy to use. Visit http://www.dovepress.com/ testimonials.php to read real quotes from published authors. 